Pietro Fratta, MD, PhD

Niranjanan

Nirmalananthan, MD, PhD*

Luc Masset*

Iwona Skorupinska*

Toby Collins, PhD

Andrea Cortese, MD

Sally Pemble, PhD

Andrea Malaspina, MD, $\mathrm{PhD}$

Elizabeth M.C. Fisher, $\mathrm{PhD}$

Linda Greensmith, PhD

Michael G. Hanna, MD, $\mathrm{PhD}$

Correspondence to

Dr. Fratta:

p.fratta@prion.ucl.ac.uk

Supplemental data at Neurology.org

\title{
Correlation of clinical and molecular features in spinal bulbar muscular atrophy OPEN
}

\section{ABSTRACT}

Objectives: To characterize the clinical and genetic features of spinal bulbar muscular atrophy (SBMA), a rare neurodegenerative disorder caused by the expansion of a CAG repeat in the first exon of the androgen receptor gene, in the United Kingdom.

Methods: We created a national register for SBMA in the United Kingdom and recruited 61 patients between 2005 and 2013. In our cross-sectional study, we assessed, by direct questioning, impairment of activities of daily living (ADL) milestones, functional rating, and subjective disease impact, and performed correlations with both CAG repeat size and degree of somatic mosaicism. Ten patients were deceased, 46 patients participated in the study, and 5 declined.

Results: Subjects had an average age at onset of 43.4 years, and weakness onset most frequently occurred in the lower limbs (87\%). Impaired mobility was the most frequently reported problem by patients, followed by bulbar dysfunction. Age distribution of the impairment of ADL milestones showed remarkable overlap with a Japanese study. We have identified a significant correlation between the number of CAG repeats and both age at onset and ADL milestones. Somatic mosaicism also showed a correlation with CAG expansion size and age at onset.

Conclusions: Clinical features in SBMA show a substantial overlap when comparing populations with different genetic backgrounds. This finding has major implications, because multicenter trials will be necessary to obtain sufficient power in future clinical trials. Clinical-genetic correlations are strong in SBMA and should inform any clinical research strategy in this condition. Neurology ${ }^{\circledR} 2014 ; 82: 2077-2084$

\section{GLOSSARY}

$\mathbf{A D L}=$ activities of daily living; $\mathbf{A L S}=$ amyotrophic lateral sclerosis; ALSFRS-R $=$ revised Amyotrophic Lateral Sclerosis Functional Rating Scale; $\mathbf{A R}=$ androgen receptor; $\mathbf{M I}=$ mosaicism index; $\mathbf{S B M A}=$ spinal bulbar muscular atrophy.

Spinal bulbar muscular atrophy (SBMA), also known as Kennedy disease, is a rare progressive neurodegenerative disorder caused by the expansion of a CAG repeat in the first exon of the gene encoding the androgen receptor (AR), which lies on the X chromosome. ${ }^{1,2}$ SBMA is characterized by the loss of lower motor neurons leading to progressive weakness in the limbs and in the bulbar musculature. ${ }^{1,3,4}$ The disease also shows a peripheral nerve sensory involvement and signs of androgen insensitivity, which manifest with gynecomastia and reduced fertility in males. ${ }^{5,6}$

The CAG expansion gives rise to a polyglutamine repeat, similar to various other neurologic disorders, termed "polyglutamine diseases." The disease manifests when the number of AR CAG repeats lies above the threshold of 38; as in other polyglutamine diseases, clinical features, such as age at disease onset, are inversely linked to the length of the expansion size. ${ }^{3,8}$ Accumulation of misfolded protein is found in patients' motor neurons and is likely to have a role in disease. ${ }^{9}$ Nonetheless, experiments on SBMA mouse models have shown that the presence of the

\footnotetext{
*These authors contributed equally to this work.

From the Department of Neurodegenerative Disease (P.F., L.M., T.C., E.M.C.F.), Sobell Department of Motor Neuroscience and Movement Disorders (N.N., L.G.), and MRC Centre for Neuromuscular Disease (P.F., N.N., I.S., A.C., E.M.C.F., L.G., M.G.H.), UCL Institute of Neurology, Queen Square, London; Neurogenetics Unit (S.P.), National Hospital for Neurology and Neurosurgery, Queen Square, London; and Centre for Neuroscience \& Trauma (A.M.), Blizard Institute, Barts and The London School of Medicine and Dentistry, Queen Mary University of London, UK.

Go to Neurology.org for full disclosures. Funding information and disclosures deemed relevant by the authors, if any, are provided at the end of the article. The Article Processing Charge was paid by University College London.

This is an open access article distributed under the Creative Commons Attribution License, which permits unrestricted use, distribution, and reproduction in any medium, provided the original work is properly cited.
} 
CAG expanded repeat is not sufficient to cause disease and that the presence of androgens is crucial for the disease to develop-which explains why women carrying the mutation are generally asymptomatic or manifest only mild symptoms, even when homozygous for the AR expansion. ${ }^{10-13}$

These findings have led to phase 2 clinical trials using agents targeting androgen synthesis and regulation. ${ }^{14,15}$ Unfortunately, no significant effects on disease course were detected; however, more sensitive outcome measures and larger numbers were thought to be essential to better assess therapeutic interventions in

\begin{tabular}{|c|c|}
\hline General study demographics and disease onset features & \\
\hline No. of living patients in register (participated in study) & $51(46)$ \\
\hline No. of deceased patients & 10 \\
\hline Age at onset, $y$, mean (range) & $43.4(14-75)$ \\
\hline Age at study, $y$, mean (range) & $57.6(19-75.9)$ \\
\hline Years of disease duration from onset, mean (range) & $16.6(0-43)$ \\
\hline CAG repeats, mean (range) & $45.5(40-53)$ \\
\hline Positive family history, \% & 71.7 \\
\hline Diagnosis before symptoms, \% & 10.8 \\
\hline Patients seen regularly by a neurologist, $\%$ & 87 \\
\hline Interval between visits, mo, median (range) & $12(2-24)$ \\
\hline Patients who underwent a muscle biopsy, \% (n) & $28.3(13)$ \\
\hline \multicolumn{2}{|l|}{ Symptom that brought to medical attention, \% (n) } \\
\hline Bulbar weakness & $6.7(3)$ \\
\hline Upper extremities weakness & $22.2(10)$ \\
\hline Lower extremities weakness & 86.7 (39) \\
\hline Breast enlargement & $6.7(3)$ \\
\hline Cramps & $6.7(3)$ \\
\hline Tremor & $13.3(6)$ \\
\hline \multicolumn{2}{|l|}{ Weakness district onset, \% (n) } \\
\hline Bulbar & $6.7(3)$ \\
\hline Upper extremities & $26.7(12)$ \\
\hline Lower extremities & $88.9(40)$ \\
\hline \multicolumn{2}{|l|}{ Symmetricity and dominance, \% } \\
\hline Asymmetrical onset & 54.5 \\
\hline Dominant side onset where asymmetrical onset & 70.8 \\
\hline Patients who received an alternative diagnosis, \% (n) & 30 (14) \\
\hline Muscle biopsy & $35.7(5)$ \\
\hline Spinal muscular atrophy & $42.9(6)$ \\
\hline Muscular dystrophy & $21.4(3)$ \\
\hline Parkinson disease & $14.3(2)$ \\
\hline Myasthenia gravis & $14.3(2)$ \\
\hline Amyotrophic lateral sclerosis & 7.1 (1) \\
\hline
\end{tabular}

this disease. ${ }^{14-16}$ To conduct such clinical trials on larger numbers of patients, a multicenter approach is necessary.

SBMA is a rare disease, and single medical centers in the United Kingdom are unlikely to follow more than 4 patients. We therefore created the first UK National Register for SBMA and here we present clinical and genetic information from 56 patients with SBMA and comparisons with the only 2 previous large clinical studies of SBMA, performed in Japan and in the United States. ${ }^{3,4}$ Our results contribute to the definition of SBMA clinical history and highlight the homogeneity of SBMA clinical features in populations with different geographic and genetic backgrounds; this has important implications for future multicenter studies.

METHODS Patients and evaluation. Patients diagnosed with SBMA were recruited through the British Neurological Surveillance Unit, an established collaborative research system run by the Association of British Neurologists. Consent was obtained directly from patients. Patients included in the register are followed in numerous centers across the United Kingdom, and DNA samples were obtained from local genetic laboratories with full informed consent where available. All participants in this study were interviewed by one research nurse specialist by telephone, with the exception of 2 patients who compiled the questionnaire by writing because of speech difficulties. There were no missing data for any of the patients who agreed to undergo interview. The questionnaire was composed of 54 questions designed to require a "yes/no" answer. Five questions, addressing the initial symptoms and major complaints, required a descriptive answer. For deceased patients, only age at onset and age at death data were included in the study.

Standard protocol approvals, registrations, and patient consents. The study was approved by the National Research Ethics Service of the UK National Health Service and local ethical committees. All patients received a patient information leaflet and signed a written informed consent form.

AR CAG repeat fragment sizing. Genomic DNA was extracted from patient peripheral blood leukocytes using a FlexiGene DNA kit (Qiagen, Venlo, the Netherlands). AR alleles were amplified by PCR using GoTaq DNA polymerase (Promega, Madison, WI) and a FAM-label introduced by the forward primer. The primers used were previously described. ${ }^{3}$ PCR products were checked on a $4 \%(\mathrm{w} / \mathrm{v})$ agarose gel and then electrophoresed on an ABI 3730xl DNA analyzer with a LIZ-500 size standard (Applied Biosystems, Foster City, CA). Fragment analysis was performed with GeneMapper software (version 4.0; Applied Biosystems).

AR CAG repeat sequencing. The CAG repeat regions of patients with SBMA were amplified by PCR using REDtaq Polymerase (Sigma, St. Louis, MO) and the primers specified by La Spada et al. ${ }^{2}$ (5'-GCCTGTTGAACTCTTCTGAGC-3' and 5'-GCTGTGAAGGTTGCTGTTCCTC-3'). Reaction mixtures were made in accordance with the manufacturer's instructions and a touchdown PCR protocol was used to reduce 
nonspecific amplification. PCR cycling conditions were 30 -second denaturing at $95^{\circ} \mathrm{C}, 30$ seconds of annealing at $72^{\circ}$ $\mathrm{C}$ (reduced by $0.5^{\circ} \mathrm{C}$ every cycle for 24 cycles), 40 seconds for extension at $72^{\circ} \mathrm{C}$, then followed by a further 10 cycles of 30 -second annealing at $95^{\circ} \mathrm{C}, 30$-second annealing at $60^{\circ} \mathrm{C}$, and 40 seconds of extension at $72^{\circ} \mathrm{C}$. The PCR product was purified from the amplification mixture using microCLEAN PCR clean-up kit (Microzone, Haywards Heath, UK), and the repeat region of interest was sequenced using ABI Prism BigDye Terminator Cycle Sequencing Ready Reaction kit version 1.1 (Applied Biosystems, Foster City, CA). Fifteen-microliter

\section{Figure 1 Age distribution of ADL milestones}

A

Age distribution of ADL milestones for 56 SBMA patients

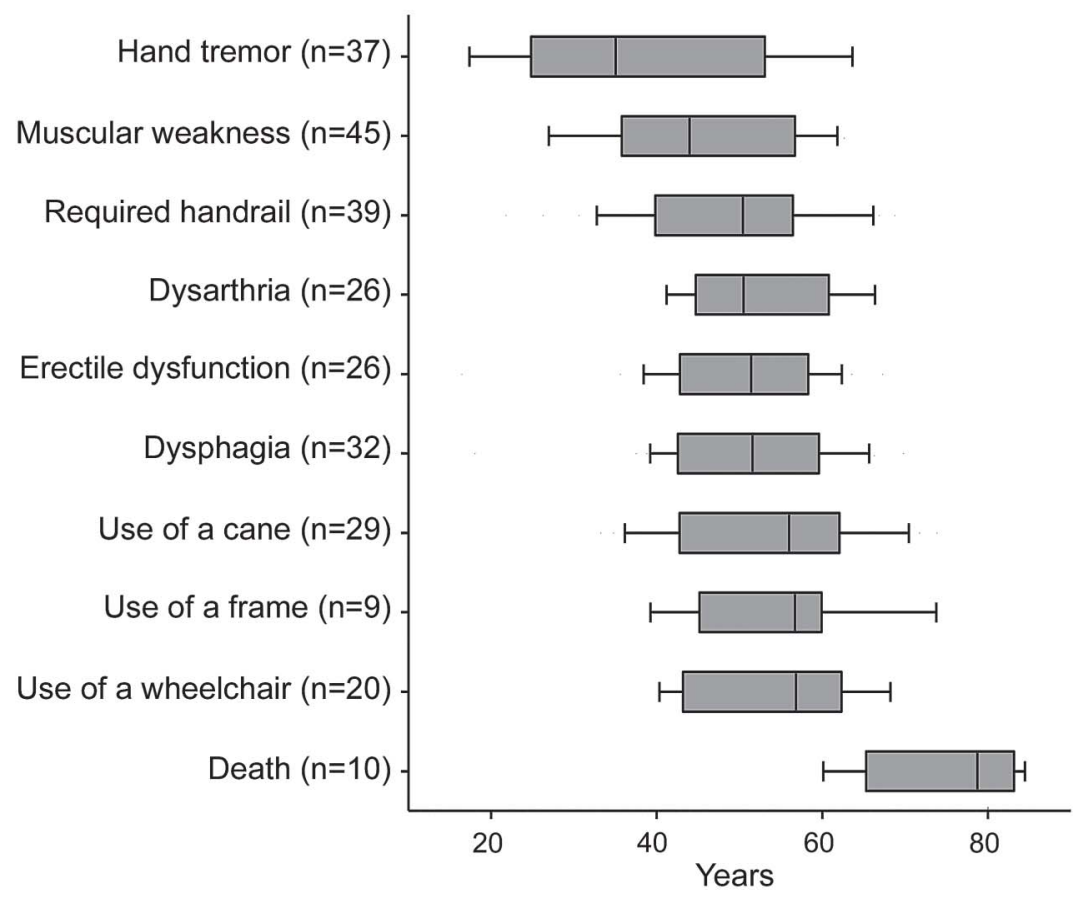

B Comparison of the ADL milestones' age distribution
between the UK and Japanese cohorts

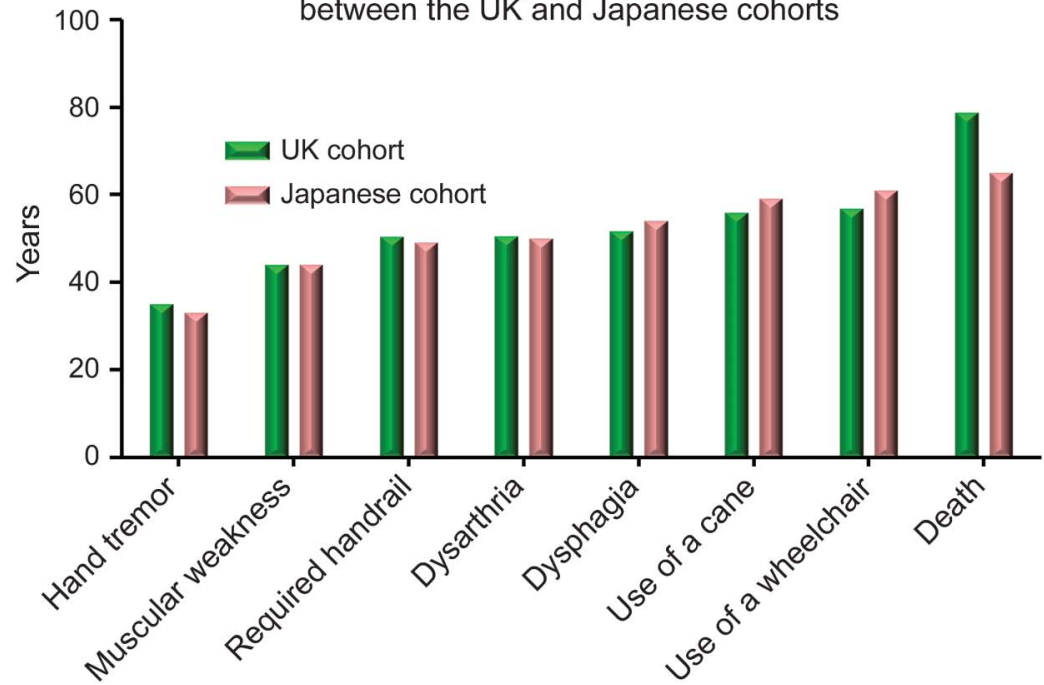

For each milestone, median age, 10th and 90th percentile (box), and range (whiskers) of age are plotted (A). Median age of ADL from the UK SBMA cohort described in this study (green) and a Japanese SBMA cohort ${ }^{3}$ (pink) are plotted (B). ADL = activities of daily living; SBMA = spinal bulbar muscular atrophy; UK = United Kingdom. sequencing reactions comprised 5 to $20 \mathrm{ng}$ of DNA template, $1 \mu \mathrm{L}$ BigDye mix, $5 \mu \mathrm{L}$ Better Buffer (Microzone), $5 \mathrm{pmol}$ of either the forward or reverse sequencing primer (same as PCR primers), $1 \mu \mathrm{L}$ betaine, and were made up with an appropriate volume of nuclease free water. Cycling parameters for sequencing were set to 300 seconds at $95^{\circ} \mathrm{C}, 30$-second denaturing at $96^{\circ} \mathrm{C}$, 15 -second annealing at $55^{\circ} \mathrm{C}, 240$-second extension at $60^{\circ} \mathrm{C}$, and repeated for 35 cycles. Sequences were precipitated in ethanol, ethylenediaminetetraacetic acid, and sodium acetate solution and further washed in $70 \%$ ethanol. Sequences were determined on a 3730xl DNA Analyzer capillary sequencer (Applied Biosciences) and analyzed with Geneious sequencing software (Biomatters, Auckland, NZ).

Evaluation of mosaicism. Fluorescent PCR fragment sizing was analyzed using Peak Scanner v1.0. The areas of the major peak and of all peaks corresponding to larger fragment sizes were calculated. Only peaks with an area $>2 \%$ of major peaks were considered. We obtained a mosaicism index (MI) by dividing the area corresponding to all minor peaks by the major peak area. Cloning of the CAG repeat was performed as previously described. ${ }^{17}$

Statistical analysis. Linear regression analysis was performed using GraphPad Prism v5.03 (GraphPad Software, La Jolla, CA).

RESULTS Clinical and genetic background. Since 2005, 61 patients with SBMA have consented to take part in the UK National Register for SBMA. Of a total of 51 living patients, 46 participated in the current study, of whom 44 were of European descent and 2 were of Indian descent. Five patients declined to undergo interview because of lack of interest. The available genetic and clinical data from 10 deceased patients were also included where relevant. The average age at the time of study was 57.6 years, and the average time from disease onset was 16.6 years. A positive family history was reported in $71.7 \%$ of participants, and $10.8 \%$ received a genetic diagnosis before symptom onset. The majority of patients (87\%) were followed regularly by a neurologist, with yearly visits in most cases (table).

Disease onset and clinical presentation. The average age of disease onset was 43.4 years (range 14-75 years). Lower limb weakness was the most common presenting symptom (86.7\%), followed by upper limb weakness $(22.2 \%)$, tremors (13.3\%), and bulbar weakness $(6.7 \%)$ (table). Onset of weakness was asymmetrical in $54.5 \%$ of cases, and in $70.8 \%$ of asymmetrical onset cases, weakness occurred on the dominant side first. Many patients (28.3\%) underwent a muscle biopsy and $30 \%$ of patients received an alternative diagnosis in the first instance. The most frequent alternative diagnosis was spinal muscular atrophy (42.9\%), followed by muscular dystrophy, Parkinson disease, myasthenia gravis, and amyotrophic lateral sclerosis (ALS) (table).

Disease progression and activities of daily living milestones. To gain information on the clinical course of the disease, we investigated the onset of decline in 
activities of daily living (ADL). The earliest deficit noticed by patients was hand tremor at a median age of 35 years, followed by muscle weakness at a median age of 43 . The sequential use of walking aids (handrail, cane, frame, and wheelchair), bulbar-related ADL milestones (dysarthria and dysphagia), and erectile dysfunction were reported between the ages of 50 and 60 years (figure 1A). Only one patient had undergone gastrostomy. Death occurred in 10 patients at a median age of 79. To investigate whether the SBMA course overlaps in cohorts with different genetic backgrounds, we plotted the median age of $\mathrm{ADL}$ milestone data from

\section{Figure 2 Cross-sectional assessment of spinal bulbar muscular atrophy} disability and symptoms

A
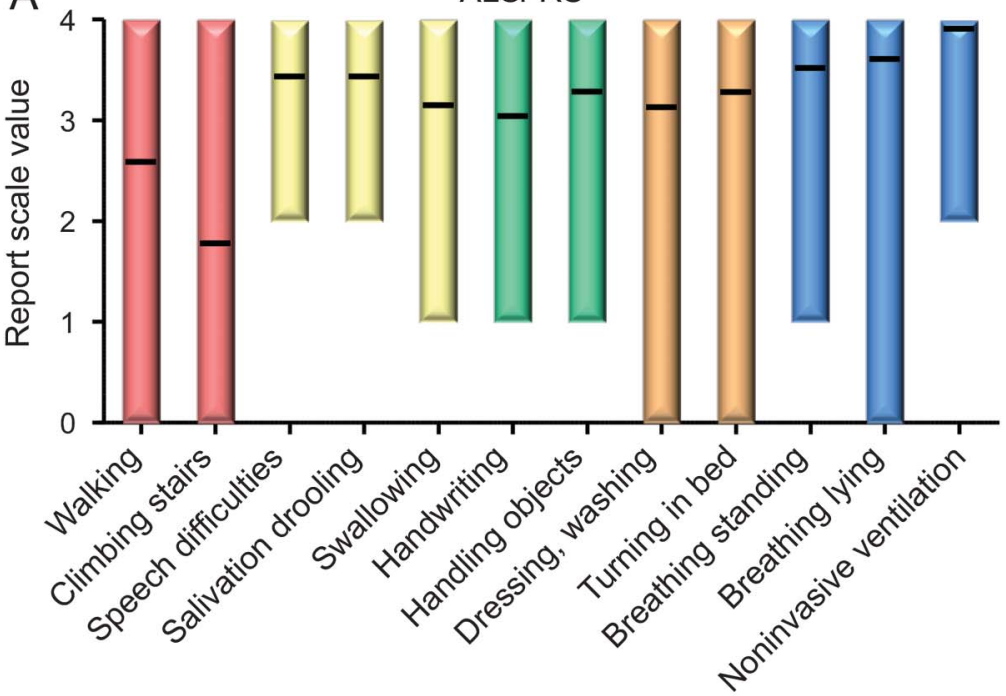

B

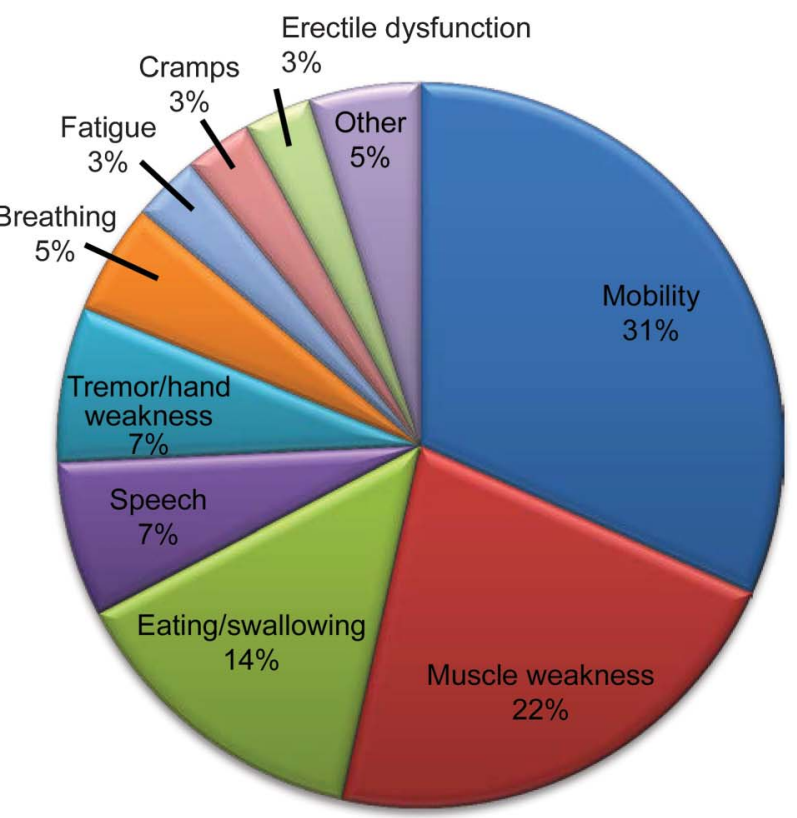

Mean score value and score range for all items of the Amyotrophic Lateral Sclerosis Functional Rating Scale (ALSFRS) are plotted (A). Participants were asked to define the 3 major problems caused by disease, and results are plotted (B). our study together with data from a large cohort $(\mathrm{n}=$ 223) described in $\operatorname{Japan}^{3}$ (figure 1B), and the data showed remarkable similarity.

Characteristic motor symptoms such as muscle cramps and muscle twitching were respectively described in $76.1 \%(\mathrm{n}=35)$ and $84.7 \%(\mathrm{n}=39)$ of patients, at a median age of 39.4 and 41.8 years. Onset of sensory symptoms, described as numbness or tingling, was noticed by $58.7 \%(\mathrm{n}=27)$ of patients, at a median age of 50 years. Breast enlargement was described by $73.9 \%$ of patients at a median age of 39.1 years (figure e-1 on the Neurology ${ }^{\circledR}$ Web site at Neurology.org).

Cross-sectional evaluation: Self-assessment testing, disease impact, and comorbidity. Participants were evaluated at the time of study using the revised ALS Functional Rating Scale (ALSFRS-R), devised to monitor progression of motor neuron disease, which considers bulbar, limb, and respiratory weakness. ${ }^{18}$ For each item, scores range from 0 to 4 , with 4 being unaffected. The average score was 38.2 (range 1848), with 48 being the maximum possible score. The most severely affected activities related to mobility, walking and climbing stairs, and these items had an average score of 2.6 and 1.8, respectively. Bulbar and upper limb linked activities followed; the least affected items were those related to the respiratory function of patients (figure 2A). We have plotted our results in parallel with results from a crosssectional study and show a similarity between the cohorts $^{19}$ (figure e-2).

We also assessed the major subjective diseaserelated disabilities by asking participants to state their 3 major disabling issues. Impairment of mobility was the most frequent complaint (31\%), followed by muscle weakness (22\%), swallowing problems (14\%), speech problems $(7 \%)$, hand tremors $(7 \%)$, breathing problems $(5 \%)$, fatigue $(3 \%)$, cramps $(3 \%)$, and erectile dysfunction (3\%) (figure $2 \mathrm{~B}$ ).

The comorbidity in our cohort consisted of $18 \%$ with diabetes and $28 \%$ had had infectious pneumonia.

CAG sizing and clinical correlations. All participants underwent genetic testing in different regional UK clinical genetics departments. Given the variability that can occur in performing fragment analysis, ${ }^{20}$ we used data on CAG expansion sizing only when performed in our institute $(\mathrm{n}=37)$ or in laboratories where the fragment analysis PCR was normalized by using a reference sample $(n=2)$ in order to obtain homogeneous data. Mean repeat size from 39 individuals was 46.03, ranging between 40 and 53 .

We plotted the CAG repeat size in relation to age at disease onset and age at onset for the major ADL milestones and clinical features and performed regression analysis. CAG repeat size significantly inversely correlated 

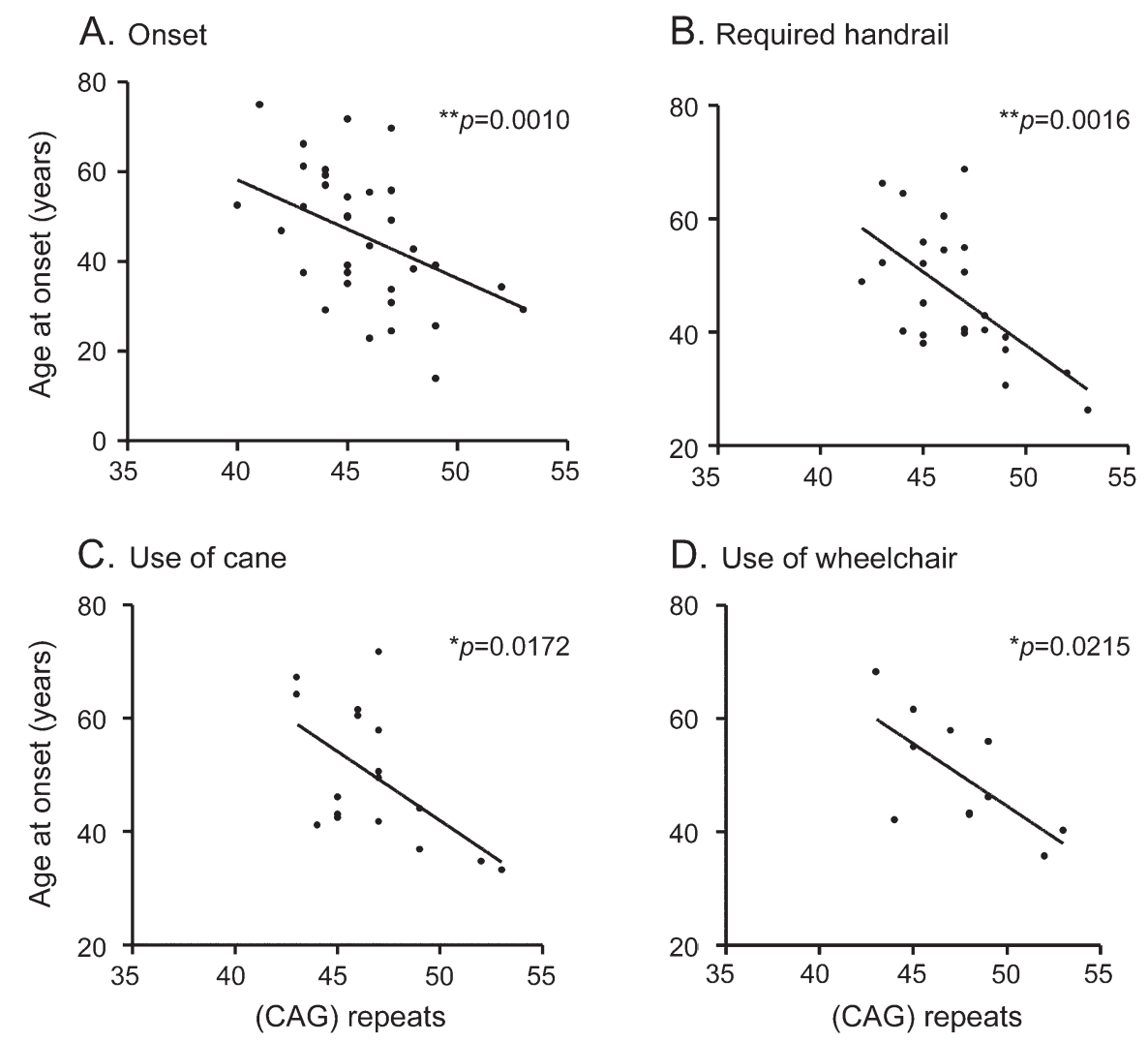

Number of CAG repeats is plotted vs disease onset (A), age when first required handrail $(B)$, age when started using a cane (C), and age when started using a wheelchair (D).

with age at disease onset, use of a handrail, use of a cane, use of a wheelchair, and muscle weakness $(p=0.0035)$ (figure 3). Other clinical features, including hand tremor, muscle twitching, muscle cramps, sensory symptoms, dysarthria, dysphagia, breast enlargement, and erectile dysfunction showed trends for an inverse correlation, but did not reach statistical significance (figure e-3).

To assess whether CAG expansion size influences disease progression, we correlated CAG repeat number with time intervals occurring between ADL milestones and found no significant association (figure e-4).

Evaluation of mosaicism and clinical correlations. Somatic instability of the repeat expansion is a feature common to the majority of microsatellite expansion disorders and has been shown to occur in numerous tissues in SBMA. ${ }^{21}$ Therefore, we investigated whether the degree of somatic mosaicism measured in blood correlated with disease clinical features.

When assessing the repeat size, using both fragment analysis and sequencing, we observed a major peak and 2 to 3 smaller peaks corresponding to both larger and smaller repeat expansions, as previously described (figure e-5B). ${ }^{21}$ All patients presented peaks on both sides of the major peak, while all tested samples with normal repeat range showed only peaks corresponding to smaller sizes (figure e-5A), which have previously been suggested to be PCR artifacts. ${ }^{21}$ To confirm the origin of the observed peaks, we PCR amplified the CAG expanded repeats and cloned and then sequenced the products, which revealed a single peak suggesting that sequencing produces no artifacts (figure 4A). We then reamplified the cloned product by PCR and observed the appearance only of peaks corresponding to smaller size repeats, thus confirming (1) that PCR amplification indeed contributes to generating smaller repeats by slippage, and (2) that the larger size peaks represent genuine somatic instability (figure 4A). Therefore, we considered only the peaks (1) corresponding to amplicons larger than the major peak, and (2) that had an area of $>2 \%$ of the major peak. The number of peaks determined by somatic mosaicism in blood is fewer than that observed in other tissues, making the count of these not very informative. To grade the mosaicism in this setting, we calculated an MI by summing the area of all extra peaks and dividing by the area of the major peak (figure 4B). CAG repeat number and MI showed a positive correlation ( $p=0.0014$ ) (figure $4 \mathrm{C}$ ), confirming results obtained in skin and muscle tissues. ${ }^{21} \mathrm{We}$ then assessed whether the MI correlated to clinical features of the disease. The MI significantly correlated 
Figure 4 Analysis of CAG repeat somatic mosaicism
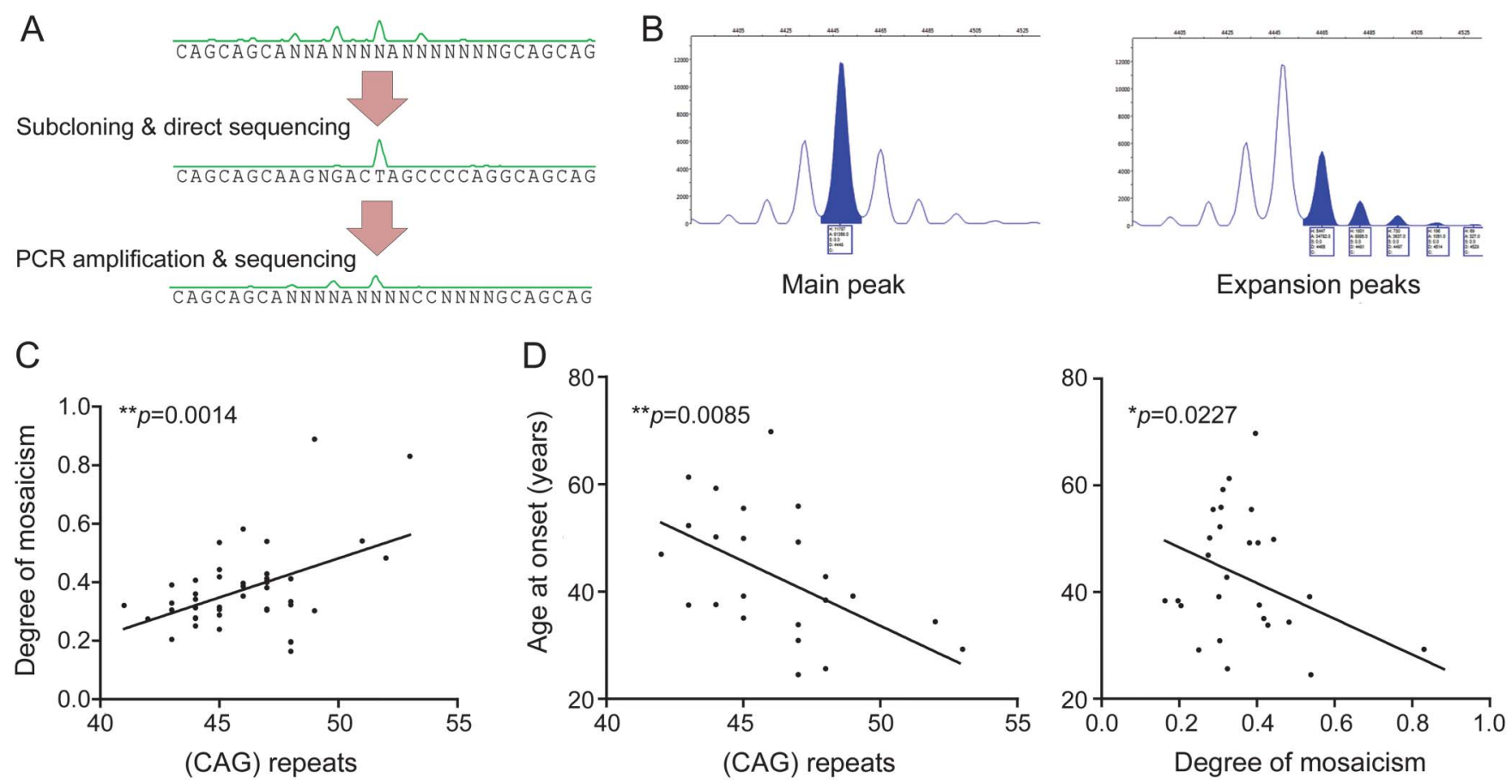

Sequence traces allow visualization of somatic mosaicism by analyzing the signal of a single T nucleotide 9 bases downstream of the repeat (A). Sequencing after cloning shows loss of extra peaks, and further reamplification shows appearance only of peaks of smaller sizes than the major peak. Example of peak area calculation performed on fragment analysis results in order to calculate the mosaicism index (MI) (B). MI is plotted with CAG repeat expansion size (C). Age at onset is plotted vs both CAG expansion repeat size and MI (D).

inversely with age at onset of disease, but correlation failed to reach significance for other clinical features and $\mathrm{ADL}$ milestones (figures $4 \mathrm{D}$ and $\mathrm{e}-6$ ).

DISCUSSION Phase 2 clinical trials have been conducted in world-leading clinical centers for SBMA in Japan, Europe, and the United States. ${ }^{14,15,22}$ However, in order to conduct any future phase 3 clinical trials, and to more efficiently translate research findings to the clinic, it is clear that large cohorts of patients and better defined information on disease course and potential geographic- and ethnic-related differences are needed. ${ }^{14,15}$ Therefore, we created the first national register for SBMA in the United Kingdom, where single medical centers are unlikely to follow up more than 4 to 5 patients, and in this study, we present the clinical and genetic information of patients participating in this register.

The general features of our study population were comparable to the 2 large previously published cohorts, including age at weakness onset (43.4 years in our study; 41 and 45.4 years in the US and Japanese cohorts, respectively) and CAG repeat length (46.03 repeats in our UK cohort; 46.6 and 46.7 in the US and Japanese cohorts, respectively). ${ }^{3,4}$

The majority $(87 \%)$ of participants are followed up by a neurologist, but this could be attributable to an overestimation bias, because the recruitment of patients occurred by contacting all British consultant neurologists through the Association of British Neurologists.

Onset of muscle weakness most frequently occurred in the lower limbs, in line with other studies, but we noticed a lower frequency of initial bulbar involvement than reported in the previous studies $(6.7 \%$, vs $13.8 \%$ and $33 \%$ in Japanese and US studies).

When onset was asymmetrical, it occurred on the dominant side in $71 \%$ of cases, which is similar to $69 \%$ previously reported. ${ }^{4}$ Of note, the increased use of the dominant side has been suggested to have a role in neuromuscular disorders; for example, asymmetry favoring the dominant side has been shown in ALS.23

One in 3 of the patients in our study received an alternative diagnosis and a similar proportion of patients underwent a muscle biopsy, showing a frequently complex workup leading to the correct diagnosis. Beyond primary myopathies and other forms of motor neuron disease, 2 patients received the diagnosis of Parkinson disease because of the presence of tremors. One in 10 patients received the genetic diagnosis before symptom onset and this number is likely to be an underrepresentation, because 5 participants received the diagnosis before genetic testing was available and a further 10 participants less than 10 years after the discovery of the genetic cause.

The variability in impairment of ADL milestones was high, but median age remarkably paralleled the 
results reported in the Japanese study, with weakness occurring at 44 years and bulbar deficits causing dysarthria and dysphagia and use of mobility aids becoming necessary between 50 and 57 years of age. The only value differing between the Japanese and our cohort is the age at death (65 vs 79 years, respectively). This difference could be attributable to the fact that our study was conducted principally on living patients participating in the UK National Register for SBMA and only basic clinical-genetic information, such as CAG repeats, date at onset, and date at death, was used for deceased patients, thus making the set of patients contributing to the age at death data different from the rest. Indeed, while the size in our study cohort was similar to the study from the Sobue group in Japan, the repeat size in the subgroup of deceased patients was smaller (43.6 vs 45.4), potentially accounting for the observed age at death difference.

The cross-sectional analysis we conducted confirmed - both by using a functional rating scale and by asking for subjective disease impact- that SBMA prevalently affects mobility at the outset to then develop into upper limb- and bulbar-related disabilities. Comparison of the results for the ALSFRS score with a cross-sectional study performed in North America $^{19}$ confirms similar disease characteristics independently of geographic differences.

Our association analysis between CAG repeats and clinical features shows a significant inverse association with age at onset and ADL mobility milestones. CAG repeat number did not correlate with disease progression, confirming previous observations by the Sobue group ${ }^{3}$ and indeed suggesting that the correlation with $\mathrm{ADL}$ milestones principally reflects the effect on age at onset.

Age at death was the only clinical milestone differing between our population and the Japanese cohort, and was the only one characterized by a different CAG repeat number; this warrants consideration of CAG repeat length in randomization and in study outcome analysis.

Somatic instability has been described in SBMA and in the majority of CAG repeat disorders. ${ }^{7} \mathrm{We}$ sought to assess the degree of blood somatic mosaicism and to determine whether there was a correlation with disease features, and indeed we found a correlation with CAG expansion size and also an inverse correlation with age at disease onset. Further studies on larger numbers will be required to assess whether the somatic mosaicism has an effect on age independently from CAG expansion size.

Our study highlights important clinical features to be considered in the care of patients with SBMA and when planning clinical trials and interventions. A limitation of our study is that it is based on interviews and is therefore subject to recollection bias. Nonetheless, our data show remarkable overlap of clinical features when analyzing
SBMA cohorts with different genetic and geographic backgrounds. This finding is of utmost importance for planning and developing future clinical trials. Indeed, SBMA is a rare disorder, and to achieve the power to detect potentially beneficial effects, future phase 2 and 3 randomized controlled clinical trials will have to be conducted with a multicenter, international approach.

\section{AUTHOR CONTRIBUTIONS}

P.F., N.N., A.C., M.G.H.: study concept and design. P.F., N.N., I.S., T.C., S.P., A.M.: acquisition of data. P.F., L.M., T.C.: analysis and interpretation of the data. P.F., N.N., E.M.C.F., L.G., M.G.H., A.M.: critical revision of the manuscript for important intellectual content. P.F., E.M. C.F., L.G., M.G.H.: study supervision.

\section{ACKNOWLEDGMENT}

The authors are grateful for the support of individuals and families involved, and thank the British Neurological Surveillance Unit and all consultant neurologists who participated in referring patients and providing clinical information.

\section{STUDY FUNDING}

This study was not sponsored by industry. This work was supported by the Medical Research Council (MRC), the Motor Neurone Disease Association (MNDA), the National Institute for Health Research University College London Hospitals Biomedical Research Centre, and the Thierry Latran Foundation. MRC/MNDA Lady Edith Wolfson Fellowship (P.F.); the National Institute for Health Research University College London Hospitals Biomedical Research Centre (P.F.); MRC Clinical Research Training Fellowship (N.N.); Institute of Neurology Kennedy's Disease Research Fund (L.G. and M.G.H.). MRC, MNDA, and TLF grants (E.M.C.F.); Clinical R\&D Committee of RF\&UCMS/UCLH Charities (L.G. and N.N.). The MRC Centre for Neuromuscular Diseases is supported by an MRC Centre grant. L.G. is the Graham Watts Senior Research Fellow, funded by The Brain Research Trust.

\section{DISCLOSURE}

The authors report no disclosures relevant to the manuscript. Go to Neurology.org for full disclosures.

Received November 9, 2013. Accepted in final form March 10, 2014.

\section{REFERENCES}

1. Kennedy WR, Alter M, Sung JH. Progressive proximal spinal and bulbar muscular atrophy of late onset: a sexlinked recessive trait. Neurology 1968;18:671-680.

2. La Spada AR, Wilson EM, Lubahn DB, et al. Androgen receptor gene mutations in X-linked spinal and bulbar muscular atrophy. Nature 1991;352:77-79.

3. Atsuta N, Watanabe H, Ito M, et al. Natural history of spinal and bulbar muscular atrophy (SBMA): a study of 223 Japanese patients. Brain J Neurol 2006;129: 1446-1455.

4. Rhodes LE, Freeman BK, Auh S, et al. Clinical features of spinal and bulbar muscular atrophy. Brain J Neurol 2009; 132:3242-3251.

5. Antonini G, Gragnani F, Romaniello A, et al. Sensory involvement in spinal-bulbar muscular atrophy (Kennedy's disease). Muscle Nerve 2000;23:252-258.

6. Dejager S, Bry-Gauillard H, Bruckert E, et al. A comprehensive endocrine description of Kennedy's disease revealing androgen insensitivity linked to CAG repeat length. J Clin Endocrinol Metab 2002;87:3893-3901.

7. Orr HT, Zoghbi HY. Trinucleotide repeat disorders. Annu Rev Neurosci 2007;30:575-621. 
8. La Spada AR, Roling DB, Harding AE, et al. Meiotic stability and genotype-phenotype correlation of the trinucleotide repeat in X-linked spinal and bulbar muscular atrophy. Nat Genet 1992;2:301-304.

9. Adachi H, Katsuno M, Minamiyama M, et al. Widespread nuclear and cytoplasmic accumulation of mutant androgen receptor in SBMA patients. Brain J Neurol 2005;128: 659-670.

10. Schmidt BJ, Greenberg CR, Allingham-Hawkins DJ, et al Expression of X-linked bulbospinal muscular atrophy (Kennedy disease) in two homozygous women. Neurology 2002;59:770-772.

11. Chevalier-Larsen ES, O’Brien CJ, Wang H, et al. Castration restores function and neurofilament alterations of aged symptomatic males in a transgenic mouse model of spinal and bulbar muscular atrophy. J Neurosci 2004;24:4778-4786.

12. Katsuno M, Adachi H, Kume A, et al. Testosterone reduction prevents phenotypic expression in a transgenic mouse model of spinal and bulbar muscular atrophy. Neuron 2002;35:843-854.

13. Mariotti C, Castellotti B, Pareyson D, et al. Phenotypic manifestations associated with CAG-repeat expansion in the androgen receptor gene in male patients and heterozygous females: a clinical and molecular study of 30 families. Neuromuscul Disord 2000;10:391-397.

14. Fernández-Rhodes LE, Kokkinis $\mathrm{AD}$, White $\mathrm{MJ}$, et al. Efficacy and safety of dutasteride in patients with spinal and bulbar muscular atrophy: a randomised placebocontrolled trial. Lancet Neurol 2011;10:140-147.

15. Katsuno M, Banno H, Suzuki K, et al. Efficacy and safety of leuprorelin in patients with spinal and bulbar muscular atrophy
(JASMITT Study): a multicentre, randomised, double-blind, placebo-controlled trial. Lancet Neurol 2010;9:875-884.

16. Katsuno M, Tanaka F, Adachi H, et al. Pathogenesis and therapy of spinal and bulbar muscular atrophy (SBMA). Prog Neurobiol 2012;99:246-256.

17. Menon RP, Nethisinghe S, Faggiano S, et al. The role of interruptions in polyQ in the pathology of SCA1. PLoS Genet 2013;9:e1003648.

18. Cedarbaum JM, Stambler N, Malta E, et al. The ALSFRS-R: a revised ALS Functional Rating Scale that incorporates assessments of respiratory function. BDNF ALS Study Group (Phase III). J Neurol Sci 1999;169:13-21.

19. Chahin N, Klein C, Mandrekar J, et al. Natural history of spinal-bulbar muscular atrophy. Neurology 2008;70: 1967-1971.

20. Fratta P, Collins T, Pemble S, et al. Sequencing analysis of the spinal bulbar muscular atrophy CAG expansion reveals absence of repeat interruptions. Neurobiol Aging 2014;35: 443.e1-443.e3.

21. Tanaka F, Reeves MF, Ito Y, et al. Tissue-specific somatic mosaicism in spinal and bulbar muscular atrophy is dependent on CAG-repeat length and androgen receptor-gene expression level. Am J Hum Genet 1999;65: 966-973.

22. Querin G, D'Ascenzo C, Peterle E, et al. Pilot trial of clenbuterol in spinal and bulbar muscular atrophy. Neurology 2013;80:2095-2098.

23. Turner MR, Wicks P, Brownstein CA, et al. Concordance between site of onset and limb dominance in amyotrophic lateral sclerosis. J Neurol Neurosurg Psychiatry 2011;82: 853-854.

\section{Visit the Neurology ${ }^{\circledR}$ Resident \& Fellow Web Site}

Click on Residents \& Fellows tab at www.neurology.org.

Now offering:

- Neurology ${ }^{\circledR}$ Resident \& Fellow Editorial team information

- "Search by subcategory" option

- E-pearl of the Week

- RSS Feeds

- Direct links to Continuum ${ }^{\circledR}$, Career Planning, and AAN Resident \& Fellow pages

- Recently published Resident \& Fellow articles

- Podcast descriptions

I Find Neurology ${ }^{\circledR}$ Residents \& Fellows Section on Facebook: http://tinyurl.com/o8ahsys

twitter Follow Neurology ${ }^{\circledR}$ on Twitter: http://twitter.com/GreenJournal 


\section{Neurology}

Correlation of clinical and molecular features in spinal bulbar muscular atrophy

Pietro Fratta, Niranjanan Nirmalananthan, Luc Masset, et al.

Neurology 2014;82;2077-2084 Published Online before print May 9, 2014

DOI 10.1212/WNL.0000000000000507

\section{This information is current as of May 9, 2014}

\section{Updated Information \& Services}

Supplementary Material

\section{References}

Citations

Subspecialty Collections

Permissions \& Licensing

Reprints including high resolution figures, can be found at: http://n.neurology.org/content/82/23/2077.full

Supplementary material can be found at: http://n.neurology.org/content/suppl/2014/05/09/WNL.0000000000000 507.DC1

This article cites 23 articles, 6 of which you can access for free at: http://n.neurology.org/content/82/23/2077.full\#ref-list-1

This article has been cited by 5 HighWire-hosted articles: http://n.neurology.org/content/82/23/2077.full\#\#otherarticles

This article, along with others on similar topics, appears in the following collection(s):

Anterior nerve cell disease

http://n.neurology.org/cgi/collection/anterior_nerve_cell_disease

Trinucleotide repeat diseases

http://n.neurology.org/cgi/collection/trinucleotide_repeat_diseases

Information about reproducing this article in parts (figures,tables) or in its entirety can be found online at:

http://www.neurology.org/about/about_the_journal\#permissions

Information about ordering reprints can be found online:

http://n.neurology.org/subscribers/advertise

Neurology ${ }^{\circledR}$ is the official journal of the American Academy of Neurology. Published continuously since 1951, it is now a weekly with 48 issues per year. Copyright () 2014 American Academy of Neurology. All rights reserved. Print ISSN: 0028-3878. Online ISSN: 1526-632X.

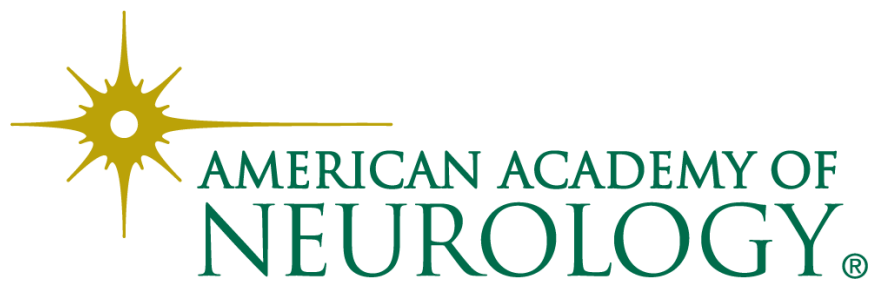

